\title{
Insect Spiracle as the Main Penetration Route of Pyrethroids
}

M. Sugiura ${ }^{1)}$, Y. Horibe ${ }^{1)}$, H. Kawada ${ }^{2)}$, M. Takagi ${ }^{2)}$

1) Research \& Development Division, Fumakilla Limited, Umehara 1-11-13, Hatsukaichi-shi, Hiroshima-ken 739-0494, Japan

Tel: +81-829-55-3433; Fax: +81-829-55-2431

E-mailः m.sugiura@fumakilla.co.jp, horibe@fumakilla.co.jp

2) Department of Medical Entomology, Institute of Tropical Medicine, Nagasaki University, Sakamoto 1-12-4, Nagasaki-shi, Nagasaki-ken 852-8523, Japan

Tel: +81-95-849-7811; Fax: +81-95-849-7812

E-mail: vergiss@nagasaki-u.ac.jp, mstakagi@nagasaki-u.ac.jp 


\section{Abstract}

The penetration route of adhered pyrethroids following direct aerosol spraying was studied in the German cockroach (Blattella germanica) by investigating the relationship between the application site of insecticide and knockdown efficacy. In direct spray, $\mathrm{KT}_{50}$ was $26.4 \mathrm{~s}$. and the adhered amount of pyrethroid was $0.745 \mu \mathrm{g}$. On the contrary, required amount of pyrethroid to obtain the same $\mathrm{KT}_{50}$ was one-eighth in topical application to the mesothoracic spiracle, while 2.6 times to the ventral mesothorax. $\mathrm{KT}_{50}$ of cockroaches with blocked mesothoracic spiracles was greater than those with unblocked spiracles by 1.8 -fold. The amount of directly sprayed pyrethroid penetrating through the inner wall of the mesothoracic trachea was significantly higher than the amount penetrating through the body wall of the ventral mesothorax. Therefore, the knockdown effect of the direct spray was believed to be caused by the flow of pyrethroids into the mesothoracic spiracles and its subsequent penetration through the inner wall of the mesothoracic trachea. 


\section{Keywords}

aerosol, pyrethroid, penetration, knockdown, spiracle, trachea, cockroach 


\section{Introduction}

There are several modes by which insecticides enter the insect body:

penetration through the integument, oral intake, and inhalation through

spiracles. It is generally assumed that contact insecticides enter the insect

body by penetrating through the integument of the body wall and

subsequent dissolution in the hemolymph $(1,2)$. Richards et al (3) suggested

that DDT is adsorbed by chitinous cuticles and that such adsorption plays a

role in insecticide action. On the other hand, Lewis (4), Matsumura, (5) and

Grissom et al (6) suggested that insecticides (DDT, malathion, and

fenvalerate, respectively) applied to the body wall accumulate in the

integument but do not diffuse freely into the hemolymph. Gerolt $(7,8)$ found that the spiracle was the most important penetration site for applied dieldrin.

These studies were performed using topical applications of insecticides. The main entry route of insecticides is assumed to differ according to the type of insecticide product (i.e., aerosol, vaporized liquid, or bait) or the application method (i.e., direct-spray aerosols, space spray, or residual spray) $(9,10)$. The major modes of entry of organophosphate insecticides, such as malathion (5), DDVP (8), or parathion (11), were also reported to be penetration through 
the integument or entry through the spiracle. According to Gerolt (8), for any insecticide, the fastest and shortest route to the target site (nervous system) is assumed to be via the spiracles. Pyrethroids are used worldwide in various household insecticidal products because of their low toxicity to mammals and their rapid knockdown effect. The rapid knockdown induced by pyrethroids simply demonstrates their rapid action on the nervous system, suggesting their mode of entry through the spiracles. However, there has been no report on the mode of entry of pyrethroids.

Aerosol insecticides are one of the most commonly and widely used insecticidal products. However, their use is regulated by the VOCs (Volatile Organic Compounds) Regulation of the Ministry of Environment. The amount of both the discharged solvent and gas should be maintained at minimum levels. Aerosol insecticides are used not only for direct spraying on insects but also for blowing into cracks and crevices $(12,13,14,15)$; the latter is one of the most important methods of pest control. ULV (ultra low volume) aerosols are also used for controlling hidden cockroaches $(16,17)$. ULV aerosol droplets enter cracks and crevices; the cockroaches hidden in these areas come into contact with the droplets. Therefore, in order to enhance 
insecticide efficacy, it would be valuable to develop a technique whereby insecticide particles adhere efficiently to the insect's body, and the adhered insecticides enter rapidly into the body. However, fundamental studies conducted to develop such techniques have been limited.

The purpose of this study was to determine the most important entry route of pyrethroids directly sprayed as aerosol particles and the behavior of the pyrethroids adhered to the insect integument.

\section{Materials and Methods}

\section{Insects used}

We used 1- to 3-month-old unanesthetized, wing-clipped adult female German cockroaches (Blattella germanica L.). The colonies were obtained from the Institute of Medical Science, University of Tokyo, Japan, and were reared on pellet food (NMF; Oriental Yeast Co., Ltd, Tokyo, Japan) in the laboratory of the Research and Development Division, Fumakilla Limited, at $\mathrm{RT}\left(27^{\circ} \mathrm{C} \pm 2^{\circ} \mathrm{C}\right)$ under a $14 \mathrm{~h}: 10 \mathrm{~h}$ light:dark (L:D) cycle. 


\section{Aerosols tested}

The aerosol used in the direct spraying efficacy test contained $0.45 \mathrm{~g}$ of d-tetramethrin (Lot. No. 81303; purity, 95.2\%; Sumitomo Chemical Co., Ltd., Tokyo, Japan) and $0.06 \mathrm{~g}$ of d-resmethrin (Lot. No. 050301; purity, 95.4\%; Sumitomo Chemical Co., Ltd, Tokyo, Japan) as active ingredients, up to 45 $\mathrm{ml}$ of $\mathrm{n}$-paraffin or isopropyl caprinate as the solvent, and $255 \mathrm{ml}$ of liquid petroleum gas (LPG) $\left(4.0 \mathrm{~kg} / \mathrm{cm}^{2} \cdot \mathrm{g}\right)$ as the propellant. The aerosol actuator was $0.45 \mathrm{~mm}$ in diameter.

The aerosol used to measure the amount of insecticide penetrating the insect body contained 4.5 g of Metofluthrin (Lot. No. 2B01; purity, 96.5\%; Sumitomo Chemical Co., Ltd, Tokyo, Japan) as an active ingredient, up to 45 $\mathrm{ml}$ of $\mathrm{n}$-paraffin or isopropyl caprinate as the solvent, and $255 \mathrm{ml}$ of LPG (4.0 $\mathrm{kg} / \mathrm{cm}^{2} \cdot \mathrm{g}$ ) as the propellant. The aerosol actuator was $0.45 \mathrm{~mm}$ in diameter.

\section{Efficacy tests}

\section{Direct spray test}

A direct spray apparatus (Fig.1) was used to conduct these tests. Eight cockroaches were placed within a glass cylinder (diameter, $9 \mathrm{~cm}$; height, 6 $\mathrm{cm}$ ); the ends of the cylinder were covered with $1.5 \mathrm{~mm}$ mesh nylon nets. Two 
grams of the test aerosol (comprising $5 \mathrm{mg} \mathrm{d}$-tetramethrin and $0.67 \mathrm{mg}$ d-resmethrin) was sprayed in the direction of the glass cylinder from a distance of $110 \mathrm{~cm}$. The number of knocked-down cockroaches was counted for 3 min after spraying, and $\mathrm{KT}_{50}$ values (time required to achieve $50 \%$ knockdown) were calculated by Bliss' probit method (18). This test was repeated 8 times. The $95 \%$ confidence limits were calculated by the $t$-test.

\section{Residual contact test}

To evaluate the influence of residual insecticide on the glass cylinder and nylon nets on the cockroaches, the glass cylinder and nylon nets were placed at the bottom of the direct spray apparatus (Fig.1) without the cockroaches, and spraying was performed in the same manner, as described above.

Subsequently, 8 German cockroaches were brought into contact with them, and the number of knocked-down cockroaches was counted for 5 min after contact. The $\mathrm{KT}_{50}$ values were calculated by Bliss' probit method (18). This test was repeated 10 times. 


\section{Topical application test involving various sites of insect body}

The abovementioned aerosol solution containing $0.45 \mathrm{~g}$ of $\mathrm{d}$-tetramethrin and $0.06 \mathrm{~g}$ of d-resmethrin as active ingredients and up to $45 \mathrm{ml}$ of $\mathrm{n}$-paraffin or isopropyl caprinate was used.

The insecticide solution was discharged from the glass capillary set in the injection holder of a microinjector (IM-300; NARISHIGE Co., Ltd, Tokyo, Japan). The amount of solution discharged was controlled by adjusting the air pressure, duration of discharge, and diameter of the hole of glass capillary. Since the amount of solution in a single discharge was too small to measure and varied depending on the diameter of the glass capillary hole, the actual amount of solution in a single discharge was calculated by weighing the amount of discharge 250 times for each glass capillary beforehand.

The wings of adult female German cockroaches were clipped. Subsequently, $52.6 \mathrm{~nL}$ of the test solution with n-paraffin ( $0.5 \mu \mathrm{g} d$-tetramethrin and 0.067 $\mu \mathrm{g}$ d-resmethrin) was applied to various sites of the insect body without anesthesia by using a substance microscope. Each insect was then released into a polyethylene cup to observe knockdown. $\mathrm{KT}_{50}$ values were calculated by Bliss' probit method (18). This test was repeated 10-30 times. The $95 \%$ confidence limits were calculated by the t-test. 
Furthermore, $1.9-13.2 \mathrm{~nL}$ and $7.9-456 \mathrm{~nL}$ of the test aerosol solution were applied to the mesothoracic spiracle and ventral thorax, respectively. Analysis was performed as described above. For each site, the regression formula was calculated by using the applied amount of d-tetramethrin and the $\mathrm{KT}_{50}$ value. These data were compared with the result of the direct spray test; the amount of insecticide used in order to obtain the same $\mathrm{KT}_{50}$ values in both the tests was compared.

The test solution $(10 \mathrm{~nL})$ with isopropyl caprinate was applied to the mesothoracic spiracle, and the efficacy of this aerosol solution was compared with that of the aerosol solution in which n-paraffin was used under the same conditions.

\section{Blocking of spiracles of cockroaches}

The wings of the adult female German cockroaches were clipped. The cockroaches were anesthetized with diethyl ether; using a stainless-steel pin, a lacquer droplet was applied on the mesothoracic spiracles of the cockroaches by using a substance microscope. The direct spray test was then performed using these cockroaches, and the $\mathrm{KT}_{50}$ values were calculated as 
described previously.

In order to elucidate the negative effect of spiracle blocking on knockdown

efficacy, 2 series of cockroach groups were prepared; one group comprised cockroaches with one side of the mesothoracic spiracles blocked, and the other group comprised cockroaches in which both sides of the mesothoracic spiracles were blocked. In both groups, $52.6 \mathrm{~nL}$ of aerosol solution was topically applied to the ventral thorax, as mentioned above. The $\mathrm{KT}_{50}$ values of these groups were compared with that of the control, and the spiracle-blocking effect was examined.

\section{Measurement of amounts of adhered pyrethroid}

\section{Measurement of pyrethroid amounts directly adhered to insect body}

For measuring the amount of pyrethroid adhered to the insects, 3 German cockroaches were pinned (stainless-steel pin, $4 \mathrm{~cm}$ in length) onto polystyrene foam chips $(2 \mathrm{~cm} \times 4 \mathrm{~cm} \times 1 \mathrm{~cm})$ and then placed at the bottom of the glass cylinder of the direct spray apparatus (Fig.1). Spraying was then performed as described previously. Subsequently, the cockroaches were immersed in approximately $10 \mathrm{ml}$ of hexane solution and ultrasonicated for 
30 min to extract the adhered insecticide. The amount of d-tetramethrin was analyzed with a gas chromatograph-mass spectrophotometer using di-n-amyl phthalate as the internal standard. The following are the details of the GC-MS analysis: model, GCMS-QP2010 (SHIMADZU CORPORATION); column, CBP1 (SHIMADZU CORPORATION) fused silica capillary GC column $(25 \mathrm{~m} \times 0.32 \mathrm{~mm}$ I.D., $\mathrm{df}=0.5 \mu \mathrm{m}) ;$ column temperature, $150^{\circ} \mathrm{C}(1$ $\min )-10^{\circ} \mathrm{C} / \mathrm{min}-300^{\circ} \mathrm{C}(2 \mathrm{~min})$; carrier gas, helium; constant linear velocity mode, $72.1 \mathrm{~cm} / \mathrm{s}$; injection temperature, $250^{\circ} \mathrm{C}$; injection method, splitless $(1$ min); injection volume, $1 \mu \mathrm{L}$; interface temperature, $250^{\circ} \mathrm{C}$; ion source temperature, $200^{\circ} \mathrm{C}$; ionization, electron impact; SIM monitoring ions, d-tetramethrin (m/z 164) and di-n-amyl phthalate (m/z 149); SIM sampling interval, $0.2 \mathrm{~s}$. This test was repeated 6 times.

\section{Measurement of pyrethroid amounts directly adhered to glass cylinder and nylon nets and re-adhered to insect body from glass cylinder and nylon nets} For measuring the amount of pyrethroid adhered to the glass cylinder and nylon nets, they were placed at the bottom of the glass cylinder of the direct 
spray apparatus (Fig.1) without the cockroaches, and spraying was then performed as described previously. Subsequently, the inner wall of the glass cylinder was washed with $50 \mathrm{ml}$ of hexane solution, and the nylon nets were immersed in approximately $50 \mathrm{ml}$ of hexane solution and ultrasonicated for 30 min to extract the adhered insecticide. The amount of d-tetramethrin was analyzed with a gas chromatograph-mass spectrophotometer as described previously. This test was repeated 5 times.

For measuring the amount of pyrethroid re-adhered to the insect body from the sprayed glass cylinder and nylon nets, they were placed at the bottom of the glass cylinder of the direct spray apparatus (Fig.1) without the cockroaches, and spraying was then performed as described previously. Subsequently, 8 German cockroaches were brought into contact with them. Thirty seconds after contact initiation, the cockroaches were immersed in approximately $10 \mathrm{ml}$ of hexane solution and ultrasonicated for $30 \mathrm{~min}$ to extract the adhered insecticide. The insecticide was then concentrated to 1 $\mathrm{ml}$ with acetone by solid-phase extraction (Bond Elut-Fl, $50 \mathrm{ml} 1 \mathrm{~m}$ (Varian, Inc)). The amount of d-tetramethrin was analyzed with a gas chromatograph-mass spectrophotometer as mentioned above. This test was 
repeated 3 times.

\section{Measurement of amount of penetrated pyrethroid}

A scanning electron microscope (SEM) and X-ray micro-analyzer (EDX) integration system (SEMEDX Type N; Hitachi Science Systems, Ltd., Tokyo, Japan) was used to conduct these tests. The material set in the SEM is eradiated electron beam and the element of the material is flipped its electrons. And then, the element eradiate its specific X-ray spectrum when outer shell's electrons are moving to inner shell. EDX detects the specific $\mathrm{X}$-ray spectrum and identifies the element. The measurement conditions were set as follows: acceleration voltage, $15.0 \mathrm{kV}$; power, $\times 200$ magnification; vacuum degree, $30 \mathrm{~Pa}$. One wing-clipped German cockroach was placed within the glass cylinder of the direct spray apparatus (Fig.1). An aerosol with n-paraffin as the solvent was sprayed toward its ventral side from a distance of $40 \mathrm{~cm}$. The amount discharged was $3 \mathrm{~g}(77 \mathrm{mg}$ of Metofluthrin, including 21.1\% molecular fluorine). The sprayed cockroaches were immersed in liquid nitrogen for 10-300 s after spraying. The aerosol with isopropyl caprinate was then sprayed in the same manner, and the 
cockroaches were immersed in liquid nitrogen for 120-300 s after spraying in order to compare these results of spraying with those obtained on spraying with the aerosol containing n-paraffin. Using a substance microscope, the frozen cockroaches were sliced with a razor at right angles to the median plate at the mesothoracic spiracle; a $3 \mathrm{~mm}$-thick slice was obtained. The slice was immediately placed onto the SEM sample holder with the mesothoracic spiracle side in the uppermost position and viewed under the SEM. The image of the slice showed the inner tissue along the mesothoracic trachea (Fig. 3) or the ventral mesothoracic segment (Fig. 4), and then 5 areas in each tissue were irradiated with the electron beam. The amount of Metofluthrin-derived fluorine that had penetrated the inner tissue at these areas was measured by detecting the specific X-ray spectrum obtained from these areas by using EDX. The measured for each area was $100 \mathrm{~s}$. The amount of Metofluthrin-derived fluorine was calculated in terms of the weight percent of all the identified elements.

These measurements were conducted at $-10^{\circ} \mathrm{C}$ to prevent any insecticide from flowing out of the tissue. This test was repeated 4-7 times (20-35 areas) in each tissue. Statistical analysis was performed using the t-test or 
repeated-measures analysis of variance (ANOVA).

\section{Results}

\section{Knockdown effect of direct spray and residual contact}

The $\mathrm{KT}_{50}$ value in the direct spray test when the discharge amount was $2 \mathrm{~g}$ (5 mg d-tetramethrin and $0.67 \mathrm{mg} \mathrm{d}$-resmethrin) was $26.4 \mathrm{~s}$, while in the residual contact test, in which the glass cylinder and nylon nets were sprayed under the same conditions, the $\mathrm{KT}_{50}$ value obtained was greater than $300 \mathrm{~s}$.

Amount of pyrethroid adhered to insect body directly and re-adhered from glass cylinder and nylon nets

The amount of aerosol solution that adhered directly to each insect was $67.6 \mathrm{~nL} \pm 14.9 \mathrm{~nL}(0.676 \mu \mathrm{g} \pm 0.149 \mu \mathrm{g} \mathrm{d}$-tetramethrin; mean $\pm \mathrm{SD})$.

The amount of aerosol solution that adhered to the glass cylinder and nylon nets was $644 \mathrm{~nL} \pm 119 \mathrm{~nL}$ and $12781 \mathrm{~nL} \pm 866 \mathrm{~nL}$, respectively $(6.44 \mu \mathrm{g}$ $\pm 1.19 \mu \mathrm{g}$ and $127.81 \mu \mathrm{g} \pm 8.66 \mu \mathrm{g} d$-tetramethrin, respectively; mean $\pm \mathrm{SD}$ ). These amounts corresponded to $0.13 \%$ and $2.5 \%$, respectively, of the 
discharged amount of the aerosol solution.

The amount of aerosol solution that was re-adhered to the cockroaches was $6.9 \mathrm{~nL} \pm 2.7 \mathrm{~nL}(0.069 \mu \mathrm{g} \pm 0.027 \mu \mathrm{g}$ of $\mathrm{d}$-tetramethrin; mean $\pm \mathrm{SD})$ during the $30 \mathrm{~s}$ contact with the glass cylinder and nylon nets.

\section{Relationship between application site of pyrethroid and knockdown efficacy}

Table 1 shows the $\mathrm{KT}_{50}$ values that were obtained when $52.6 \mathrm{~nL}$ of the aerosol solution containing $0.5 \mu \mathrm{g} d$-tetramethrin and $0.067 \mu \mathrm{g} d$-resmethrin was applied at different sites of the cockroach body. The knockdown time was fastest when the insecticide was applied to the mesothoracic spiracle, and the $\mathrm{KT}_{50}$ value at this site was significantly different from that obtained at other sites ( $p<0.05 ; \mathrm{t}$-test). The application of the aerosol solution to the ventral mesothorax and abdominal spiracle also caused knockdown.

However, the $\mathrm{KT}_{50}$ values obtained on insecticide application to the above 2 sites were much lower than that obtained on application to the mesothoracic spiracle. 
Relationship between amount of pyrethroid applied to the spiracle and mesothorax and knockdown efficacy

Fig.2 shows the relationship between the amount of d-tetramethrin applied to the mesothoracic spiracle and ventral mesothorax and the $\mathrm{KT}_{50}$ value of this treatment. According to the regression formulae indicated in fig.2, the needed amounts of d-tetramethrin to obtain the same $\mathrm{KT}_{50}$ value as direct spray (26.4 s.) by application to the mesothoracic spiracle and the ventral mesothorax were calculated on $0.093 \mu \mathrm{g}$ and $1.97 \mu \mathrm{g}$, respectively.

\section{Knockdown effect of directly sprayed aerosol on cockroaches with blocked mesothoracic spiracles}

The $\mathrm{KT}_{50}$ values of the cockroaches with one side of the mesothoracic spiracle blocked and those of cockroaches in which the spiracles were not blocked were not significantly different (41.9s and $42.1 \mathrm{~s}$, respectively, $\mathrm{p}<$ 0.05; $\mathrm{t}$-test,). On the contrary, the $\mathrm{KT}_{50}$ values of cockroaches with both sides of the mesothoracic spiracle blocked and those of cockroaches with unblocked spiracles were significantly different $(29.9 \mathrm{~s}$ and $42.1 \mathrm{~s}$, respectively, $\mathrm{p}<0.05$; t-test). Therefore, it was assumed that conducting aerosol efficacy tests with both sides of the mesothoracic spiracles blocked was not appropriate since 
this affected the insecticide susceptibility of cockroaches.

The $\mathrm{KT}_{50}$ values of the cockroaches with one side of the mesothoracic

spiracle blocked and those of cockroaches with unblocked spiracles were 46.3 s and $26.4 \mathrm{~s}$, respectively. Thus, the $\mathrm{KT}_{50}$ value of the cockroaches with one side of mesothoracic spiracles blocked was greater than that of the cockroaches with unblocked spiracles by 1.8 -fold. A significant difference was observed in these $\mathrm{KT}_{50}$ values. $(\mathrm{p}<0.05$; $\mathrm{t}$-test, Table 2 ).

\section{Penetration of pyrethroids through different sites}

The fluorine in sprayed cockroaches was determined to be Metofluthrin-derived since no fluorine was found in the controls. The amount of Metofluthrin-derived fluorine in the peripheral tissue of the mesothoracic trachea was significantly higher than that in the inner tissue of the ventral mesothoracic segment $(\mathrm{p}<0.001$; repeated-measures ANOVA, Table.3).

A large amount of fluorine was observed in the peripheral tissue as early as $10 \mathrm{~s}$ after spraying, and this amount gradually decreased with time. The amount of fluorine that penetrated the peripheral tissue of the mesothoracic 
trachea was 1.9-8.6 times that of the fluorine in the inner tissue of the ventral mesothoracic segment (Fig.5).

\section{Relationship between different solvents and knockdown efficacy}

Table 4 shows the $\mathrm{KT}_{50}$ values of the cockroaches that were directly sprayed with an aerosol solution and subjected to topical application of an aerosol solution containing d-tetramethrin and d-resmethrin. In both the tests, n-paraffin caused a significantly higher knockdown effect than isopropyl caprinate $(\mathrm{p}<0.05 ; \mathrm{t}$-test).

The amount of Metofluthrin-derived fluorine that penetrated the inner tissue of the mesothoracic spiracle was significantly higher when n־paraffin was used as the insecticide solvent instead of isopropyl caprinate; however, no significant difference in penetration of the inner tissue of the ventral mesothorax was observed between the 2 solvents $(\mathrm{p}<0.05$; $\mathrm{t}$-test, Table 5$)$

\section{Discussion}

In Insects, many studies have been conducted for determining the relationship between insecticide susceptibility and the insecticide 
application site. Wilcoxon et al (19) assumed that the difference in insecticide susceptibility was associated with the thickness of the cuticle and with the degree of sclerotization; thin areas such as sense organs, spiracles, and intersegmental membranes allowed rapid penetration, while thick areas such as body segments and appendages were less permeable. Others considered sclerotization of little importance, and the speed of insecticide action was believed to depend on the distance between the point of application and the site of action, i.e., the central nervous system (CNS). Thus, the ventral prothorax and the sites close to the CNS results in the quickest response, and the points situated further away result in slower responses $(4,7,8,11,20,21)$. Differences in knockdown efficacy depending on the application site have been reported $(22,23)$; for example, in the German cockroach, insecticide application on the head yielded a quicker response than that on the abdomen or legs. The present test results also indicate that insecticide application on the ventral mesothorax that is close to the CNS results in comparatively rapid knockdown, while insecticide application to sites further away from the CNS results in very slow responses. However, the topical application of insecticides on the abdominal 
spiracles results in a quicker response than insecticide application on the labium or the dorsal membrane of the head and thoracic area although these areas are closer to the CNS than the abdominal area. Moreover, insecticide application to the mesothoracic spiracle, which is situated closest to the CNS, results in the quickest response. These facts indicate that insecticide entry from the spiracles, particularly from the mesothoracic spiracle, plays an important role in mediating a rapid knockdown effect.

When a pyrethroid aerosol is sprayed, the probability of sufficient adhesion of the insecticide at a site near the CNS for causing knockdown is assumed to be low, and the quantity of insecticide that penetrates the tissue is also small. Nevertheless, the response of the sprayed insect is very rapid. Since in this study, the $\mathrm{KT}_{50}$ value of direct spray was $26.4 \mathrm{~s}$, it seems reasonable to consider that the actual amount of the insecticide that participated in achieving the resultant knockdown efficacy is a sum of the insecticide adhered directly and re-adhered due to the $30 \mathrm{~s}$ of residual contact. Therefore, the total effective adhesion amount of solution in direct spray was estimated at $74.5 \mathrm{~nL}(0.745 \mu \mathrm{g}$ d-tetramethrin), i.e., $67.6 \mathrm{~nL}+6.9$ $\mathrm{nL}$. On the other hand, the present test results indicate that the required 
amount of pyrethroid to obtain the same $\mathrm{KT}_{50}$ as the direct spray was one-eighth in topical application to the mesothoracic spiracle, while 2.6 times in topical application to the ventral mesothorax. Since the condition of adhesion to the insect body in direct spray is widely considered in comparison with topical application, it is possible to adhesion to the site which is more susceptive than ventral mesothorax in direct spray. Moreover, our results indicated that the mesothoracic spiracle is 20 times more susceptible to insecticides than the ventral mesothorax. These results suggest that the rapid knockdown of insects by the directly sprayed pyrethroid method is mainly caused by the flowing of the insecticide into the mesothoracic spiracle and its sequential penetration through the inner wall of the mesothoracic trachea. In addition, these test results indicate that directly sprayed pyrethroid flows rapidly (within $10 \mathrm{~s}$ ) into the mesothoracic spiracle and penetrates the peripheral tissue and the inner wall of the mesothoracic trachea. The fact that pyrethroid sprayed onto insects with one side of their mesothoracic spiracles blocked was less efficacious, indicates that insecticide movement into the mesothoracic spiracle is an important cause of knockdown. In insects with blocked spiracles, the amount of 
insecticide that penetrated into the body surface and flowed into spiracles other than the mesothoracic spiracle, were considered to be similar to that in insects with unblocked spiracles. On the other hand, the amount of insecticide flowing into the mesothoracic spiracle was assumed to be less in insects with blocked spiracles than in insects with unblocked spiracles, resulting in slower knockdown.

Gerolt (8) suggested that insecticides that adhered to the insect body migrated laterally and reached the CNS via the integument of the tracheal system and not via the blood after penetration into the tissue. Our test results also show that the entry of insecticides via the spiracles is important for knockdown efficacy. However, insecticides that penetrate the peripheral tissue of the mesothoracic spiracle also appear to play an important role.

Moreover, we demonstrated that the insecticidal solution containing $\mathrm{n}$-paraffin has a greater knockdown effect than that containing isopropyl caprinate, and greater amounts of directly sprayed insecticide penetrated the peripheral tissue of the mesothoracic spiracle when n-paraffin was used as the solvent. The efficacy of an insecticide in an aerosol formulation depends on the solvent type (24). Our results also show that very little 
isopropyl caprinate penetrates the peripheral tissue of spiracles, and that most of the insecticide is absorbed through the inner wall of the trachea without reaching the target organ, thus decreasing its effectiveness. It therefore seems that the penetration speed of the solvent into the inner wall of the trachea plays an important role in knockdown efficacy.

It is thought that the entry of insecticides via the spiracles is important for insecticide efficacy (8); however, further studies are necessary to clarify the route by which insecticides reach the target organ from the spiracle, i.e., whether it is through the inner wall of the tracheal system or directly into the CNS. 


\section{Acknowledgments}

We would like to thank the staff of the Research \& Development Division,

Fumakilla Limited, for rearing the cockroaches and analyzing the insecticides. We also thank the members of the Department of Medical

Entomology, Institute of Tropical Medicine, Nagasaki University, for their advice and cooperation. 


\section{References}

(1) W. Ebeling, Permeability of insect cuticle, in:Rockstein M. (Eds.), The Physiology of Insecta, Vol. 3, Academic Press, New York, 1964, pp. 507-556.

(2) F. P. W. Winteringham, Comparative biochemical aspects of insecticidal action, Chem. Ind. (1957) 1195-1202.

(3) A. G. Richards, L.K. Cutkomp, Correlation between the possession of a chitinous cuticle and sensitivity to DDT, Biol. Bull. Woods Hole, 90 (1946) 97-108.

(4) C. T. Lewis, Influence of cuticle structure and hypodermal cells on DDT absorption by Phormia terranovae R-D, J. Insect Physiol. 11 (1965) 683-694.

(5) F. Matsumura, The permeability of the cuticle of Periplaneta americana

(L.) to malathion, J. Insect Physiol. 9 (1963) 207-221.

(6) R. E. Grissom Jr, T. Konno, N. Motoyama, W. C. Dauterman, Comparison between in vivo and in vitro cutaneous penetration of fenvalerate in tobacco budworm (Lepidoptera:Noctuidae), J. Econ Entomol. 82 (1989) 41-44.

(7) P. Gerolt, The fate of dieldrin in insects, J. Econ. Entomol. 58 (1965) 850-857.

(8) P. Gerolt, Mode of entry of contact insecticides, J. Insect Physiol. 15 
(1969) 563-580.

(9) A. Hayashi, Practice of pest control and insecticide, Nanzan-Do Press, Japan, 1983, pp. 4-8.

(10) K. Yasutomi, Guidance of chemical methods for the control of insect pests, Life and Environment. 32 (1987) 30-33.

(11) H. J. Ball, S. D. Beck, The role of the circulatory and nervous system in the toxic action of parathion, J. Econ. Entomol. 44 (1951) 558-564.

(12) P. A. Zongori, W.H. Robinson, Crack and crevice outshines fan-spray treatment, Pest Control. 50 (1982) 20, 22.

(13) G. W. Bennett, J. W. Yonker, Crack and crevice application of chlorpyrifos against the German cockroach, Insectic. Acaric. Tests. 11 (1986) 442.

(14) J. L. Health, T. D. Spittler, Determination of the technique of using a compressed air sprayer that optimizes applicator safety and cockroach control efficacy, Pest Management. 4 (1985) 12-14, 16-18.

(15) G. A. Braness, G. W Bennett, Residual effectiveness of insecticides for control of German cockroaches (Dictyoptera: Blattellidea) in food-handling establishments, J. Econ. Entomol. 83 (1990) 1907-1911. 
(16) C. D. McNeal, G. W. Bennett, Utilization of ULV aerosols for control of the German cockroach, J. Econ. Entomol. 69 (1976) 506-508.

(17) R. C. Moore, Field tests of pyrethrins and resmethrin applied with ULV generators or total release aerosols to control the German cockroach, J. Econ. Entomol. 70 (1977) 86-88.

(18) C. I. Bliss, The method of probits—a correction, Science. 79 (1934) 409-410.

(19) F. Wilcoxon, A. Hartzell, Some factors affecting the efficiency of contact insecticides. III. Further chemical and toxicological studies of pyrethrum, Contrib. Boyce Thompsom Inst. 5 (1933) 115-127.

(20) R. W. Fisher, The importance of the locus of application on the effectiveness of DDT for the house fly, Musca domestica L. (Diptera: Muscidae), Can. J. Zool. 30 (1952) 254-266.

(21) W. C. O'Kane, G.L. Walker, H. G. Guy, O. J. Smith, Reactions of certain insects to controlled applications of various concentrated chemicals, II. A new technique for initial appraisal of proposed contact insecticides, Studies of contact insecticides IV, N. H. Agricultural Experiment Station, Tech. Bull. 54 (1933) 1-23. 
(22) J.G. Scott, F. Matsumura, Evidence for two types of toxic actions of pyrethroids on susceptible and DDT-resistant German cockroaches, Pestic. Biochem. Physiol. 19 (1983) 141-150.

(23) J.G. Scott, S. B. Ramaswamy, F. Matsumura, K. Tanaka, Effect of Method of application on resistance to pyrethroid insecticides in Blattella germanica (Orthoptera: Blattellidae), J. Econ. Entomol. 79 (1986) 571-575. (24) S. Tsuda, I. Nishibe, G. Shinjo, Effect of the diameter of spray droplets on the insecticidal efficacy of oil-based aerosols, J. Pestic. Sci. 12 (1987) 483-489. 
Fig.1: Image of the direct spray apparatus used for performing the aerosol direct spray test.

Fig.2: Relationship between the amount of applied d-tetramethrin ( $\mu \mathrm{g} /$ individual) by topical application of aerosol solution and $\mathrm{KT}_{50}$ values at each site of the insect body.

The regression formula at each application site is indicated in the figure.

Adhesion amount of d-tetramethrin and the $\mathrm{KT}_{50}$ value during direct aerosol spraying is also indicated in the figure.

Error bars represent the $95 \%$ confidence limit ( $\mathrm{t}$-test).

Fig.3: Image of the inner tissue along the mesothoracic trachea of the German cockroach.

Five square areas represent the measurement sites of the penetrated fluorine.

Fig.4: Image of the inner tissue along the ventral mesothoracic segment in the German cockroach. 
Five square areas represent the measurement sites of the penetrated fluorine.

Fig.5: Changes in the percentage of penetrated Metofluthrin-derived fluorine at each measurement site with time elapsed after aerosol spraying.

The error bars represent the $95 \%$ confidence limit at each measurement time (t-test). 